\title{
A CATHETER MOUNT FOR DOUBLE-LUMEN ENDOBRONCHIAL TUBES
}

B. E. WELSH, M.B., B.S., F.f.A.R.C.S.(ENG.), AND A. W. CoNn, M.D., F.r.C.P.(c)

DOUBLE-LUMEN ENDOBRONCHIAL TUBES have several advantages in emergency situations.

1. They permit passage of a suction catheter down one bronchus while ventilating the opposite lung. This is of particular importance if the emergency is due to conditions of the "wet lung" type, or intrabronchial bleeding from pulmonary vessels. $^{1}$

2. Ventilation to one lung may be closed off if necessary as in repair of bronchopleural fistula. ${ }^{1}$

3. Either lung may be ventilated at need in the course of the operation, as in cases involving trauma to both lungs. ${ }^{2}$

4. Solutions may be instilled into first one bronchus and then the other, and removed by suction, as in the lavage treatment of status asthmaticus. ${ }^{3}$

In such emergency situations we have found the usual methods of connecting the double-lumen tube to the anaesthetic circuit ${ }^{4}$ to have some disadvantages:

1. If the catheter mounts are already attached, the endobronchial tube is clumsy and awkward to pass.

2. If the catheter mounts are not attached, ventilation might be delayed by difficulty making the connection.

The catheter mount here described (Figs. 1, 2, and 3) was designed to overcome these problems. The basic principle is that slip mounts are used to connect the tube as soon as it is satisfactorily passed. Without being attached to the mount the tube can be inserted easily: subsequent attachment to the anaesthetic circuit is quick and certain.

We circumvent the problem of differential ventilation by inserting a slotted rotating barrel within the body of the catheter mount, allowing ventilation of either or both lungs as desired (Fig. 4), The Magill-type suction union used to connect the catheter mount to the tube makes suction of the occluded lung possible. The device and its connection into an anaesthetic circuit are shown in Figure 3.

Originally, Nosworthy slip mounts were attached to the catheter mount. This device was used successfully for two years at the Newcastle-on-Tyne regional cardiothoracic unit in England. We now would specify the usual $15 \mathrm{~mm}$ endotracheal tube connections instead of the Nosworthy mounts. 

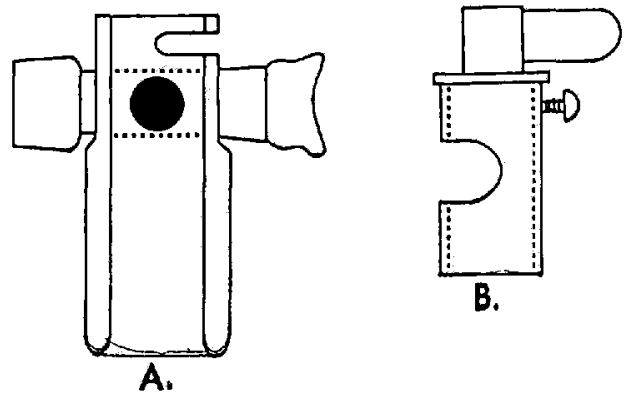

\section{PLAN ELÉVATION (Section at level slot)}

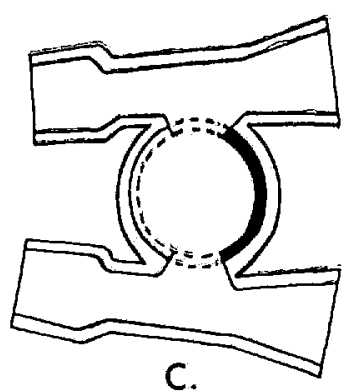

Figure 1. Sectional view of catheter mount (A) and rotating barrel (B) and cross section of cathaton monest revith hnoml in nlono 1 ol

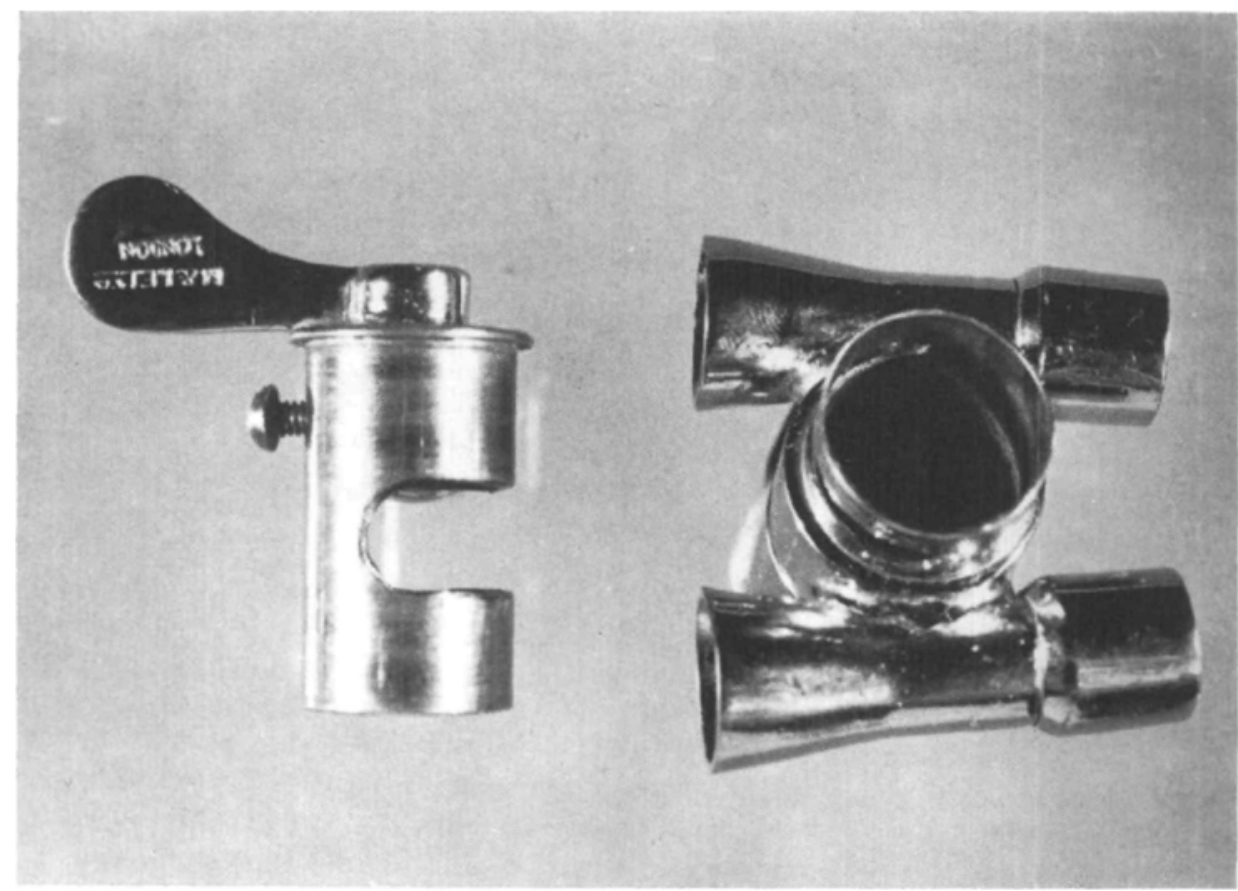

Figure 2. Photograph of mount and barrel disassembled. 


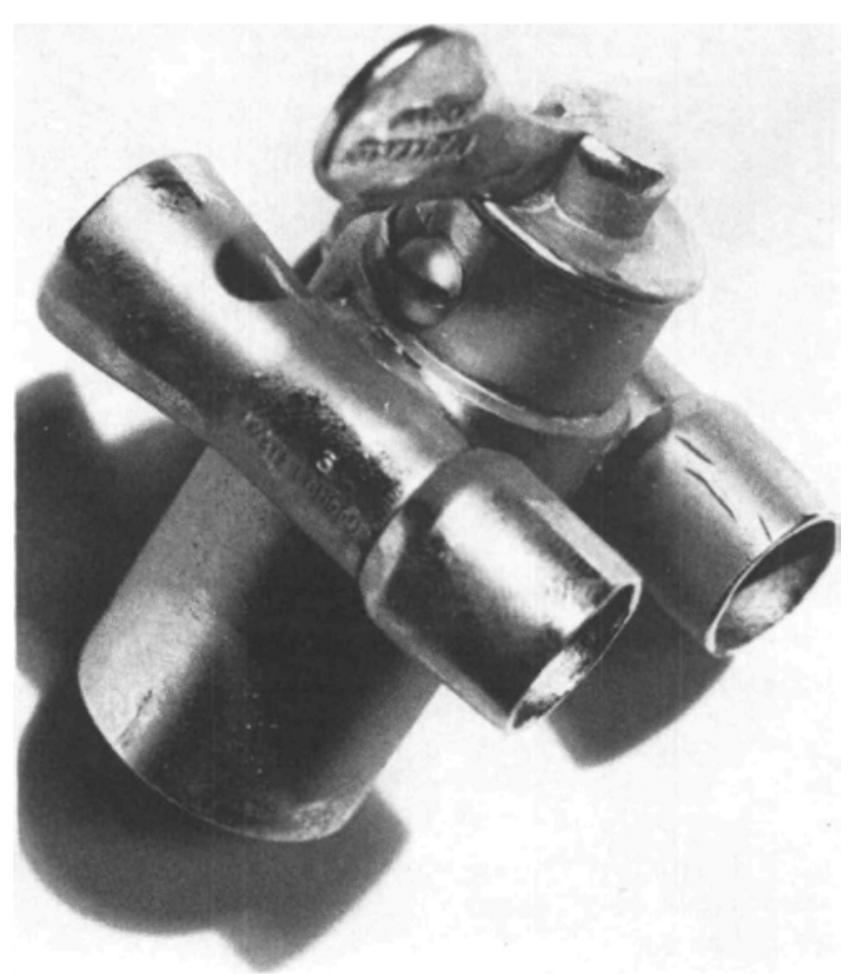

Figune 3. Photograph of mount and barrel assembled.

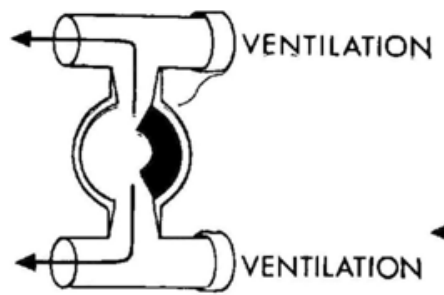

a. BOTH LUNGS VENTILATED

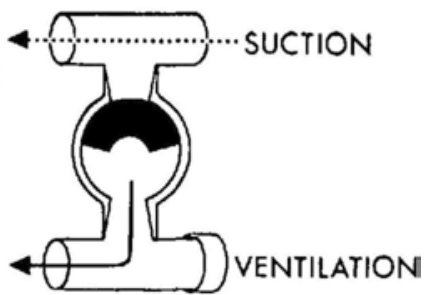

b. UNILATERAL USE

Figure 4. Diagram showing operation of catheter mount fitted with barrel. 


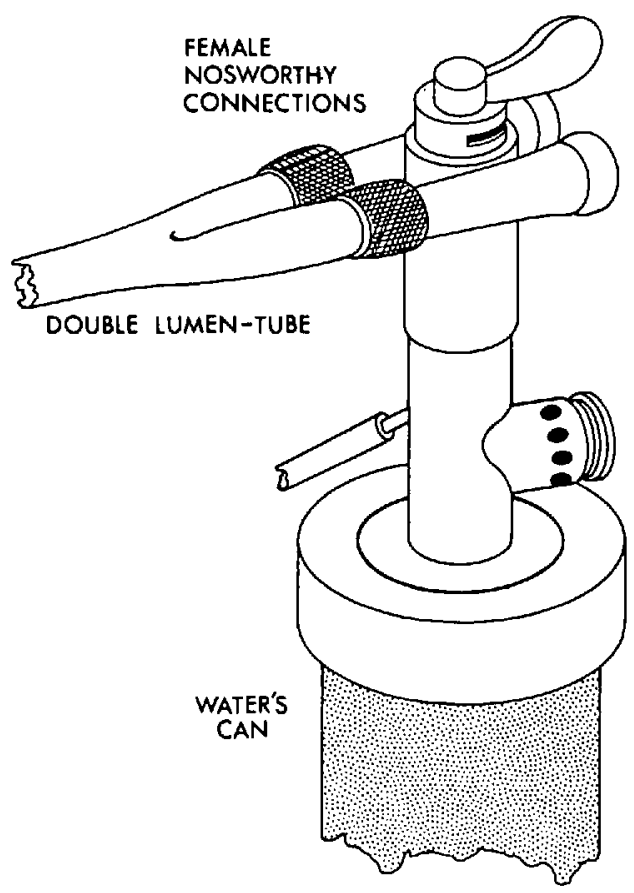

Figure 5. Device connected to anaesthetic circuit.

\section{ACKNOWLEDGMENTS}

My thanks are due to Dr. E. J. Millar and Dr. B. E. W. T. Ritchie for advice in the design and construction of the device.

\section{REFERENCES}

1. Francis, J. G. \& Smith, K. G. An Anaesthetic Technique for the Repair of Bronchopleural Fistula. Brit. J. Anaesth. 34: 817 ( 1962 ).

2. Edwards, E. M. \& Hatch, D. J. Experiences With Double-Lumen Tubes. Anaesthesia. 20: 461 (1965).

3. Birley, D. M. The Management of Bronchial Lavage. Biomed. Eng. 2: 346 (1967).

4. Mushis, W. W., ed. Thoracic Anesthesia. Oxford: Blackwell Scientific Publications (1963). 